\title{
Adaptation of Chemistry Perception Questionnaire into Turkish: A Validity and Reliability Study with Exploratory and Confirmatory Factor Analysis
}

\author{
Cemal TOSUN* \\ Bartin University, Bartin, TURKIYE
}

Received: 21.10 .2012

Accepted: 05.06.2013

\begin{abstract}
The purpose of this study is to adapt "Chemistry Perception Questionnaire (CPQ)", developed by Wells (2003), into Turkish and investigate validity and reliability of the Turkish version of the scale. The original version of the scale was composed of 35 items gathered under seven factors (aptitude, chemophobia, discipline, ethnicity, gender, instruction and value). First, permission from the developers of the scale was sought. Then, the items of the scale were translated into Turkish by researcher. The translation validity of the scale was examined by referring to the views of English and Turkish language experts. Once the final form of the scale had been derived, an English language expert translated the items of the scale from Turkish to English. The results obtained from this translation indicated that the Turkish version scale closely approximated to the original scale. Turkish version of the scale was administered to total of 435 university students from Education, Science and Engineering Faculties of Bartin, Kirikkale, Kilis 7 Aralik and Mustafa Kemal Universities. The item-total correlations were calculated and items which had negative or low correlation with the total scale score were excluded from the scale. The construct validity of the scale was examined by exploratory and confirmatory factor analysis. Varimax rotation technique was used due to the separation into irrelevant factors. Finally the scale was constructed from 20 items gathered under five factors (gender, value, chemophobia, discipline, aptitude). The reliability coefficient (Cronbach Alpha) for the whole scale was calculated as .745.
\end{abstract}

Key words: Chemistry Perception Questionnaire, CPQ, perception, validity and reliability, exploratory factor analysis and confirmatory factor analysis.

DOI No: http://dx.doi.org/10.12973/nefmed157

\section{Summary}

Many instruments have been developed that attempt to assess chemistry attitudes or anxiety. Chemistry attitude instruments tend to contain statements that might be better characterized as science and math attitudes or attitudes toward a specific course or program. Further, these instruments frequently include statements of belief or opinion.

\footnotetext{
"Corresponding author: Cemal TOSUN, Assist. Prof. Dr., Education Faculty, Bartin University, Bartin, TURKIYE.

E-mail: cemaltosun22@gmail.com
} 
According to many researchers, attitudes and beliefs should not be considered the synonyms. Attitudes refer to a common and include positive or negative feeling about an attitude object. A belief is information that a person accepts to be true (Wells, 2003). For example, the statement, "I like chemistry" is an attitude because it expresses a positive or negative feeling about chemistry. Existing chemistry anxiety instruments contain statements that would more properly come under the constructs of math or test anxiety. Therefore, they lack construct validity for the construct they claim to assess, that of chemistry anxiety.

To correct the deficiencies of previous instruments, Wells (2003) developed a measuring instrument called the Chemistry Perception Questionnaire (CPQ) to serve as a data-collection tool to assess students' chemistry perceptions. The instrument attempted assess perceptions, instead of attitudes, because it is a broader construct that also includes beliefs and opinions. CPQ has seven factor (aptitude, chemophobia, discipline, ethnicity, gender, instruction, and value) and 35 Likert-scale items. Every factor has 5 items.

\section{Methodology}

The purpose of this study was to adapt CPQ into Turkish and investigate validity and reliability of the Turkish version of the scale. In this study, general scanning model has been employed. The study was carried out through six consecutive steps. In step 1, before starting the adaptation of the scale into Turkish, necessary permissions from Raymond R. Wells, the developers of the scale, were taken via e-mails. In step 2, the scale items were translated into Turkish by the researcher. In step 3, English language experts rated the translation validity. In step 4, Turkish language experts rated the items of the Turkish scale according to accurate use of Turkish language. In step 5, the Turkish scale was translated back into English by an English language expert. The researcher examined the similarities of each item by comparing each item's original English version and its translation back into English. Finally, retranslated English items were translated into Turkish. In step 6, the English and the Turkish scales were then applied to a group of 30 volunteer students who were asked to examine the degree of harmony between two forms of the scale. Finally, validity and reliability of the translated scale was examined. The reliability of data gathered from students by the scale was examined Cronbach's Alpha. To test the construct validity of student data, the items of the scale were subjected to explanatory and confirmatory factor analysis. Subsequent to verifying the linguistic equivalence of scale, the validity and reliability analyses have been conducted via SPSS 15 and LISREL 8.8 programs. 


\section{Results and Discussion}

The results showed that there was a high level of agreement between the original and Turkish translation of the items. The Turkish scale was found to be sound in its language structure and was rated as understandable by the raters. Correlations between the English and Turkish scale scores showed that there was a high level of agreement. The item-total correlations were calculated on the data collected as evidence of validity of scale. At the end of the analysis, one item which had low correlation with the total scale score was excluded from the scale. The suitability of data for factor analysis was determined by KMO (KaiserMeyer-Olkin) parameter and Bartlett's Sphericity test. The results showed that the obtained data was suitable for exploratory factor analysis and then the construct validity of the scale was examined by exploratory factor analysis. Varimax rotation technique was used due to the separation into irrelevant factors and nine items which were excluded from the original scale. At the end of the analysis the scale was constructed as five factors and 20 items. The first factor was named as "gender", second as "value", third as "chemophobia", fourth as "discipline", and fifth as "aptitude". The findings obtained from the confirmatory factor analysis and reliability analysis showed that there was a good fit between the hypothesized model and the observed data. The standardized factor loadings were reasonable and statistically significant. Fit indices generated by the LISREL 8.8 program showed that the model fitted the data well $\left(\mathrm{X}^{2} / \mathrm{sd}=2.88 ; \mathrm{GFI}=.90 ; \mathrm{AGFI}=.87 ; \mathrm{CFI}=.92 ; \mathrm{NNFI}=.090 ; \mathrm{RMR}=\right.$ .072; RMSEA=.066). The reliability coefficient (Cronbach Alpha) for the whole scale was calculated as .745. Analysis of the data showed that the Cronbach Alpha values of the five subscales varied between .445 and .864 . Hence, the adapted scale not only managed to produce reliable data, but also valid information about the multidimensionality of data.

\section{Conclusion and Suggestion}

To conclude, a valid and reliable Turkish version of the CPQ composed of 20 items and five factors was developed. Thus, the Turkish version of the scale acquired capability of measuring Turkish university students' perceptions toward chemistry. In addition, the Turkish scale gives the Turkish teachers an opportunity to reveal students' perceptions in five dimensions. The sample of the study is limited to 435 students in four different universities. It is believed that data from different students sample would provide more evidences related to the validity and reliability of the Turkish scale. 


\title{
Açımlayıcı ve Doğrulayıcı Faktör Analizi ile Kimya Algı Ölçeği'nin Türkçe'ye Uyarlanması
}

\section{Cemal TOSUN ${ }^{+}$}

\author{
Bartın Üniversitesi, Bartın, TÜRKİYE
}

Makale Gönderme Tarihi: 21.10.2012

Makale Kabul Tarihi: 05.06.2013

Özet - Bu araştırmanın amacı, Wells (2003) tarafından geliştirilen "Kimya Algı Ölçeği (Chemistry Perception Questionaire-CPQ)"nin Türkçe'ye uyarlanarak geçerlik ve güvenirlik çalışmasını yapmaktır. Ölçek 7 faktörlü (eğilim, tedirginlik, kimyanın kapsamı, etnisite, cinsiyet, öğretim ve değer) yapıda toplam 35 maddeden oluşmaktadır. İlk olarak ölçeğin geliştiricilerinden izin alınmıştır. Daha sonra, ölçek maddeleri araştırmacı tarafından Türkçeye tercüme edilmiştir. Ölçeğinin tercüme geçerliği için İngilizce ve Türkçe dil uzmanlarının görüşlerine başvurulmuştur. İngiliz dili uzmanı tarafından son halini alan Türkçe formun İngilizceye geri çevirisi yapılmıştır. Bu aşamalardan elde edilen sonuçlar, ölçek maddelerinin Türkçe tercümesinin İngilizce orijinal maddelerle yüksek oranda örtüştüğünü göstermiştir. Böylece ölçeğin tercüme ve dil geçerliği tamamlanmıştır. Ölçeğin Türkçe formu Bartın, Kırıkkale, Kilis 7 Aralık ve Mustafa Kemal Üniversitelerinin Eğitim, Fen ve Mühendislik Fakültelerinde öğrenim gören toplam 435 öğrenciye uygulanmıştır. Madde geçerliğine kanıt olarak madde toplam test korelasyonları hesaplanmış, ölçek puanlarıyla negatif ve çok düşük korelasyona sahip olan maddeler çıkarılmıştır. Ölçeğin yapı geçerliği açımlayıcı ve doğrulayıcı faktör analizi ile incelenmiştir. Faktör analizi uygulanmasında ölçeğin ilişkisiz faktörlere ayrılması nedeniyle varimax dik döndürme tekniği kullanılmıştır. Analiz sonucunda ölçek beş faktörlü ve 20 madde olarak bulunmuştur. Ölçeğin güvenirliği (Cronbach Alpha) iç tutarlılık katsayısı toplam ölçek için .745 olarak hesaplanmıştır.

Anahtar kelimeler: Kimya Algı Ölçeği, KAÖ, algı, geçerlik ve güvenirlik, açımlayıcı faktör analizi ve doğrulayıcı faktör analizi.

\section{Giriş}

Günümüzde fen ve teknolojide baş döndürücü değişismler yaşanmaktadır. Bu değişimler ileri teknoloji gerektiren işlerde en azından minimum seviyede fen ve teknolojiden anlayan insan gereksinimi de beraberinde getirmektedir. Milli Eğitim Bakanlığı (MEB) Talim Terbiye Kurulu Başkanlığı 2011 yılında, ilköğretim ve ortaöğretim ders öğretim programlarını yeniden düzenlemiştir. Bu öğretim programlarında kimyanın genel amaçlarından birinin, "madde ve maddeler arası etkileşimler ile ilgili temel kavramlar hakkında bireylerin bilgi sahibi olmasını sağlamak, bu kavramların tarihsel gelişimi, bireysel, sosyal, ekonomik ve

\footnotetext{
† İletişim: Cemal TOSUN, Yrd. Doç. Dr., Eğitim Fakültesi, Bartın Üniversitesi, Bartın, TÜRKIYE.

E-mail: cemaltosun22@gmail.com
} 
teknolojik dünyaya etkileri ve çevre ile ilişkileri ekseninde bilinç geliştirmek” olduğu ifade edilmektedir (MEB, Talim Terbiye Kurulu Başkanlığı, 2011). Bu bilinci kazandırabilmek ve ileri teknoloji gerektiren işlerde, ülke olarak daha fazla pay sahibi olabilmek için sadece mühendislerimizin veya program geliştiricilerimizin değil, her vatandaşımızın merkezi bir bilim dalı olan kimya hakkında yeterli bilgiye sahip olması gerekmektedir.

Fen programlarında öğrenim gören lisans öğrencileri için temel kimya bilgilerine sahip olmanın ihtiyaç olduğu ve bu ihtiyacın gün gittikçe arttığı günümüzde pek çok lisans öğrencisi bu konuda yeterli eğitimi almamaktadır. Ülkemizde devlet/vakıf üniversitelerinde kimya programlarını tercih eden öğrenci sayısı da her geçen gün azalmaktadır. Bir yandan bu azalmanın nedenlerinin bir yandan da kimya programlarını tercih edenlerin kimyayla ilgili algılarının belirlenmesi önemlidir. Ayrıca kimya programlarında öğrenim gören başarılı ve başarısız öğrencilerin kimya algıları farklı mıdır? $\mathrm{Bu}$ programlarda öğrenim gören öğrencilerin algıları, öğretmenlerinden nasıl etkilenir? Öğrencilerin kimya alg1 düzeylerine göre farklı öğretim/işe alma teknikleri kullanılabilir mi? Farklı cinsiyetteki öğrencilerin kimya algıları arasında herhangi bir ilişki var mıdır? Bu ve buna benzer sorulara cevap verebilmek için öncelikle geçerliği ve güvenirliği test edilmiş bir ölçekle, öğrencilerin kimya algılarını belirlemek gerekmektedir.

Koballa (1988)'ya göre, duyuşsal değişkenlerden özellikle tutum, yıllardır fen eğitimcilerin dikkatini çekmiştir (aktaran, Wells, 2003). Fen derslerinden kimyayla ilgili olarak da, öğrencilerin kimya tutumlarını ve endişelerini değerlendirmek için pek çok ölçek geliştirilmiş, bir o kadar ölçeğin de Türkçe' ye uyarlanması çalışması yapılmıştır (örn., Bowen, 1999; Eddy, 1996). Kimya tutum ölçekleri özellikle derse, programa veya fene/matematiğe karşı tutumu belirlemeye yönelik ifadeler içermektedir. Bu nedenden dolayı, bu tür ölçeklerle bir inancı veya fikri ölçmek mümkün değildir. Tutum ve inanç birbirinden farklı kavramlardır ve kendine has öz nitelikleri olduğundan eş anlamlı kelimeler olarak düşünülmemelidir (Wells, 2003). Tutum cümlelerinde daha çok tutum objesi hakkında pozitif veya negatif bir his vardır. Örneğin "ben kimyadan hoşlanıyorum” ifadesi bir tutum ifadesidir. Çünkü o ifade kimya hakkında pozitif veya negatif bir his içermektedir. "Kimya derslerinde erkekler bayanlara göre daha iyidir" ifadesi tutum yerine bir inanç ifadesidir. $\mathrm{Bu}$ yüzden bu tür algıların da keşfedilmesi önemlidir. Mevcut kimya endişe ölçekleri ise genelde öğrencilerin test/matematik endişelerini içeren ifadelerden oluşmaktadır. Bu nedenden dolayı, bu tür ölçeklerin öğrencilerin kimya endişelerini değerlendirdiğini iddia etmek, o ölçeğin yap1 geçerliğinin eksikliğini gösterir. 
Wells (2003) tutum ve endişe ölçeklerinde var olan eksiklikleri göz önünde bulundurarak, öğrencilerin kimya algılarının ölçülmesi için, fikir ve inançları da içeren "Kimya Algı Ölçeği (Chemistry Perception Questionnaire, CPQ)'ni” geliştirmiştir. Bu çalışmada ise, Wells (2003) tarafından, geliştirilen “Kimya Algı Ölçeği (KAÖ) 'nin Türkçe’ye uyarlanması amaçlanmıştır.

\section{KAÖ’nün Gelişim Süreci}

Wells (2003) tarafından geliştirilmiş olan KAÖ, beşli likert tipinde 35 madde ve her birinde 5 madde bulunan 7 alt boyuttan oluşmaktadır. Bu 7 alt boyutun isimleri şöyledir; eğilim, tedirginlik, kimyanın kapsamı, etnisite, cinsiyet, öğretim ve değer.

Greenfield (1997)'a ve Rennie \& Dunne, (1994)'ye göre tutum ve algı birbirinden farklı kavramlardır. Bazı araştırmacılara göre algı, tutumla eş anlamlı veya onu da kapsayan bir kavramdır (örn., Cost, 2000; Ost \& White, 1979; Yager \& Bonnstetter, 1984; aktaran, Wells, 2003). Peterson \& Yaakobi, (1979)'ye göre algı, birinin başkalarının davranışlarını nasıl algıladığıdır (aktaran, Wells, 2003).

Bazı araştırmacılara göre ise tutum ve inanç birbirinden farklı kavramlardır. Ancak bazı tutum ölçeklerindeki ifadeler, inanç ifadesi olarak da sınıflandırılabilir. Tutum ve inanç kelimeleri arasında yapılan ayrım nedeniyle bu çalışmada kullanılan algı çok daha genel bir kavramdır ve tutum ve inanç kavramlarının her ikisini de içermektedir. Barman (1997) ise, bakış açısı ve algıyı birbiri yerine kullanmıştır. Bu nedenden dolayı çalışmanın amacı tutum, bakış açısı, inanç ve fikir olarak tanımlanan algıdır.

Wells (2003), çalışmasında lise ve daha üst seviyelerdeki öğrencilerin kimya algılarını belirlemek için geliştirdiği ölçeğin, geçerlik ve güvenirlik çalışmasını üniversite öğrencileriyle yapmıştır. Araştırmacı, geliştireceği ölçekteki maddelerin oluşumuna rehberlik etmesi için, algıya yönelik yukarıdaki görüşler çerçevesinde kuramsal temel olarak hizmet edecek yedi alt boyut belirlemiştir. Ayrıca ölçeğin her alt boyutu ilgili olduğu kavramla beraber incelenmiştir. Mesela eğilim alt boyutu öz-yeterlik alt boyutunun da incelenmesini gerektirmektedir. Diğer taraftan tedirginlik ise kaygı ile ilişkilidir. Tutum ise tüm alt boyutlarla ilgili olmasına rağmen öğretim alt boyutunda incelenmiştir. Yedi alt boyuttan etnisite alt boyutu Türkçe'ye uyarlanması çalışmasında uzman görüşleri doğrultusunda ölçekten çıkartılmıştır. Geriye kalan altı alt boyutun içerikleri ve seçilme nedenleri aşağıda sırasıyla verilmiştir: 


\section{Alt boyut: Ĕ̈ilim}

Öğrencilerin kimya yeteneği veya kimyaya ilgisi, bu alt boyuttaki algı ifadelerini oluşturmaktadır. Eğilim alt boyutu öz yeterlikle ilişkilidir ve öğrencilerin kendilerine olan güvenleriyle ilgili inanç ifadelerini içermektedir. Deboer (1987)'e göre, fen yeteneğine sahip olan öğrenciler, fen derslerini sürekli alma eğilimindedir (aktaran, Wells, 2003). Farklı grupların farklı düzeyde algı göstermesi nedeniyle kimya derslerine duyulan ilgi ve ön bilgilerle ilgili algıların belirlenmesi önemlidir. Bu alt boyuttaki "kimya dersini ilginç buluyorum" ifadesi olumlu cümle yapısındadır. Bu ifadeye katılmak yüksek düzeyde kimya ilgisinin göstergesidir ve beş puanla değerlendirilmektedir. Diğer taraftan "kimyada başarılı olabilmek için yeterli fen alt yapısına sahip değilim" ifadesi olumsuz cümle yapısındadır. Bu ifadeye katılmak ise düşük düzeyde kimya ilgisinin göstergesidir ve bir puanla değerlendirilmektedir.

\section{Alt boyut: Tedirginlik}

Bowen, (1999) tarafindan öğrencilerin kimya ve kimya laboratuarındaki kayg1 düzeylerini belirlemeye yönelik ölçek geliştirilmiştir. Eddy (1996)'e göre, tedirginlik üniversite dersliklerinde ve laboratuarlarında karşılaşılan gerçek doğa olayıdır. Yaptı̆ı çalışmada üniversite öğrencilerin kimya ve kimyasallar hakkındaki endişeleri arasında önemli bir ilişkinin olduğunu tespit etmiştir. Mevcut kimya endişe ölçeklerindeki ifadelerin test/matematik endişesini belirlemeye yönelik ifadeler olduğu görülmektedir. Bu ölçeğin tedirginlik alt boyutu ise, kimya ve kimyasallarla ilgili korku veya kaygı durumlarıyla ilgili algı ifadelerini içermektedir. Bu alt boyuttaki ifadelerin hepsi olumsuz madde yapısındadır. "Kimya dersinin adını duymak bile beni korkutuyor" ifadesine katılmak yüksek düzeyde korku ve kaygının göstergesidir ve bir puanla değerlendirilmektedir.

\section{Alt boyut: Kimyanin Kapsamı}

Kimyanın doğası gereği çok zor bir bilim dalı olduğu algısı vardır. Lawrenz (1976), on iki ülkenin ortaöğretim öğrencileriyle yaptığı çalışmada fizik ve biyoloji derslerinden sonra en zor dersin kimya olduğunu belirlemiştir (aktaran, Wells, 2003). Algıyı değerlendiren bir ölçek için katılımcıların cevaplarında yüksek bir varyans istenir. Bu durum ölçekte yer alan algı ifadelerinde herkesin aynı fikirde olmasının iyi bir bilgi sağlamadığının göstergesidir. Genelde kimyanın doğası hakkında öğrenciler ve öğretmenlerin aynı fikirde olmadığı gözlenmektedir. Bu nedenden kimya biliminin doğasıyla ilgili ifadelerle, öğrenci algılarının belirlenmesi önemlidir. Bu alt boyuttaki "kimyada başarll olabilmek için bilimsel bir zihin 
yapısına sahip olmak zorundayı"” ifadesi olumlu cümle yapısındadır. Bu ifadeye katılmak kimya biliminin doğası gereği özel beceriler gerektirdiğinin göstergesidir ve beş puanla değerlendirilmektedir. Diğer taraftan "kimya bilimi çok fazla matematik içermektedir" ifadesi olumsuz cümle yapısındadır. Bu ifadeye katılmak ise kimya biliminin çok fazla matematik özelliği ve niteliği nedeniyle ulaş1lamaz olduğunun göstergesidir ve bir puanla değerlendirmektedir.

\section{Alt boyut: Cinsiyet}

Kadınlarında kimya bilimiyle ilgilendikleri kabul edilmektedir. Burkam, Lee \& Smerdon, (1997)'a göre, fizik biliminde kadınlar ve erkeklerin başarı oranları arasında, 10. sınıfta önemli farklar oluşmaktadır. Genelde kimyanın erkeksi bir bilim olduğu düşünülür. $\mathrm{Bu}$ sebepten dolayı da cinsiyet alt boyutunda algı ifadelerine yer verilmiştir. Bu alt boyuttaki algı ifadeleri cinsiyetin kimya öğrenebilme becerisinde/kariyerinde başarılı olunup olunmayacağının belirlenmesi için önemlidir. Bu alt boyuttaki ifadelerin hepsi olumsuz madde yapısındadır. "Kimya alanında erkekler bayanlara göre daha iyidir" ifadesine katılmak, öğrencilerin kimya başarısında/kimya öğrenebilme yeteneğinde cinsiyetin önemli bir etken olduğunun göstergesidir ve bir puanla değerlendirilmektedir.

\section{Alt boyut: Öğretim}

$\mathrm{Bu}$ alt boyutta kimya derslerinin nasıl öğretildiğiyle ilgili algı ifadelerine yer verilmiştir. $\mathrm{Bu}$ alt boyut, tutum tartışmasını da içermektedir. Tutum cümleleri genel ifadelerdir ve tutum objesi hakkında uzun süreli pozitif veya negatif his içermektedir. İnanç ise bir insanın doğrularıdır. Tutum ve inanç arasında var olan bu fark nedeniyle öğrencilerin kimya dersine karşı tutumlarını ve inançlarını da içeren kimya dersine karşı algı düzeylerini belirleyecek bir ölçek geliştirmenin nedenini açıklar. Bu alt boyuttaki "kimya dersine çalışmak çok zaman almaktadır" ifadesine katılmak, kimyanın istenilmeyen niteliğinin göstergesidir ve bir puanla değerlendirilmektedir. Diğer taraftan "kimya eğitmenleri iyi öğretmenlerdir" ifadesine katılmak ise kimyanın istenilen bir niteliğinin göstergesidir ve beş puanla değerlendirilmektedir.

\section{Alt boyut: Değer}

Kimyanın değeriyle ilgili algıların anlaşılması önemlidir. Wells (2003)'e göre, sadece kimyanın önemini/değerini alt boyut olarak ele alan hiçbir çalışmaya rastlanılmamaktadır. Bu alt boyut kişisel olarak veya toplum olarak kimyanın önemiyle ilgili algı ifadelerini içermektedir. Bu alt boyuttaki "kimya, toplumu olumlu yönde etkilemektedir" ifadesine katılmak yüksek düzeyde kimyanın toplum için değerli olduğunun göstergesidir ve beş puanla 
değerlendirilmektedir. Diğer taraftan "kimya yarardan çok zarar verir" ifadesine katılmak ise düşük düzeyde kimyanın toplum için değerli olduğunun göstergesidir ve bir puanla değerlendirilmektedir.

Wells (2003), kuramsal çerçevesini yedi alt boyuta dayandırdığı alg1 ölçeğinin maddelerini oluşturmak için, öncelikle alan yazın çalışmaları sonrasında algı ifadelerini belirlemiştir. CPQ' nun ilk hali 58 maddeden oluşmuştur. Bu algı ifadelerinin yapı ve içerik geçerliği 5 uzman tarafından irdelenmiştir. Uzman görüşleri sonrasında madde sayısı 35'e düşürülmüştür. Kimya alg1 ölçeği pilot olarak bir öğrenci grubuna uygulanarak ölçekteki ifadeler için madde analizi yapılmıştır. Öğrencilerin tek tek ölçek maddelerine ve yedi boyuta yönelik cevaplarının güvenirlikleri, test tekrar test yöntemiyle analiz edilmiştir. Her bir alt boyut için Cronbach Alpha değerleri hesaplanmıştır. Madde analizi sonrasında gerekli değişimler yapılarak KAÖ geliştirilmiştir.

35 maddeye karşılık gelebilecek öğrenci cevapları 5'li likert tipi bir ölçek kullanılarak değerlendirilmiştir. Tamamen katılıyorum (5), katılıyorum (4), kararsızım (3), katılmıyorum (2) ve tamamen katılmıyorum (1) şeklinde. Araştırmacı, uygulanması kolay ve uzun zaman almayan bir ölçek geliştirmek için ölçeğin son halinde, yedi boyutun her biri için en geniş madde puanı-toplam puan ilişkisini sağlayan yedi madde almıştır. Bu yedi madde toplam varyansın \%72.3'ünü açıklamaktadır. Ana çalışma için, yedi boyutlu 35 maddelik ölçeği, 282 öğrenciye uygulamıştır. Verilerin yapı geçerliğini test etmek için ise, açımlayıcı faktör analizi kullanılmıştır. Orijinal ölçeğin yedi boyutuna ait Cronbach Alpha değerleri .725-.917 arasında belirlenmiştir.

\section{Yöntem}

\section{Araştırma Modeli}

Araştırmada genel tarama modeli kullanılmıştır. Genel tarama modelleri, evren hakkında genel bir fikir edinmek amacıyla evrenin tümü ya da ondan alınacak bir örneklem üzerinde yapılan tarama çalışmalarını kapsamaktadır (Büyüköztürk, Kılıç-Çakmak, Akgün, Karadeniz \& Demirel, 2010; Karasar, 2005). Bu yöntem ile tutum inanış ve görüş gibi bilgi türlerinin belirlenmesi sağlanır (McMillan \& Schumacher, 2006).

\section{Çalışma Grubu}

Aaraştırmacı tarafından Türkçe' ye tercümesi yapılan ölçeğin her bir maddesinin İngilizce-Türkçe uyumu tercüme geçerliği incelenmiştir. Çalışmanın bu aşamasına doktora sonrası eğitimi için yurt dışına (İngilizce eğitim veren üniversitelerde) giden iki ve Türkiye'de 
değişik üniversitelerde görevli en az doktora öğrenimini tamamlamış ve iyi derecede İngilizce bilen altı olmak üzere toplam sekiz kişi katılmıştır.

Daha sonra, "Türkçe formun dil ve anlam geçerliği " incelenmiştir. Bu aşamaya ise üniversitelerin Edebiyat Fakültelerinin Türk Dili ve Edebiyatı ile Eğitim Fakültelerin Türkçe Eğitimi bölümlerinde öğretim elemanı olarak görev yapan dört ve MEB'e bağlı okullarda Türk Dili ve Edebiyatı Öğretmenliği yapan ve en az 15 yıllık meslek deneyimine sahip iki olmak üzere toplam altı kişi katılmıştır.

Bu aşamadan sonra Şencan (2005)' in ifade ettiği gibi Türkçe' ye çevirisi yapılan ölçek maddeleri yeniden İngilizceye tercüme edilerek, orijinal ölçeğin İngilizce ifadeleri ile Türkçe'ye çevirisi yapılan ölçek maddelerinin yeniden İngilizceye çevrilmiş ifadeleri arasındaki uyumluluk incelenmiştir. Bu aşamada, her iki kültüre yakın bir kişi ve araştırmacı görev almıştır.

Daha sonra, ölçeğin İngilizce formu ve oluşturulan Türkçe form aynı öğrenci grubuna uygulanarak ölçeğin İngilizce ve Türkçe formu arasındaki tutarlılık incelenmiştir. Çalışmanın bu aşamasına katılacak adaylarda ölçek maddelerinin İngilizce formunu anlayabilecek derecede İngilizce bilme şartı aranmıştır. $\mathrm{Bu}$ amaçla bu aşamaya, ülkemizin değişik üniversitelerin farklı bölümlerinde yüksek lisans ve doktora öğrenimine devam etmekte olan 16 öğrenci ve Boğaziçi Üniversitesi Eğitim Fakültesi Fen Bilgisi Öğretmenliği lisans programının farklı sınıflarında öğrenimlerine devam etmekte olan ve yeterli (Proficiency) seviyede İngilizce bilen 14 öğrenci olmak üzere toplam 30 öğrenci katılmıştır.

Son olarak, ölçeğin geçerlik ve güvenirlik çalışması 4 farklı üniversitede (Bartın Üniversitesinden 167, Mustafa Kemal Üniversitenden 106, Kilis 7 Aralık Üniversitesinden 62 ve Kırıkkale Üniversitesinden 103) öğrenim gören toplam 435 öğrenci ile yürütülmüştür. Bu öğrenciler üniversitelerin Eğitim, Mühendislik ve Fen Fakültelerinin lisans programlarında (Fen Bilgisi Öğretmenliği, Sınıf Öğretmenliği, Kimya Bölümü ve Çevre Mühendisliği Bölümü) öğrenim gören $254 \mathrm{k1z}, 105$ erkek ve cinsiyetini belirtmeyen 77 öğrenciden oluşmaktadır. Örneklem seçiminde tesadüfî olmayan örnekleme yöntemlerinden amaçlı (purposive sampling) ve uygunluk örnekleme (convenience sampling) yöntemi kullanılmıştır. Uygunluk örnekleme yönteminin seçiminde, uygulamaya katılacak bireylerin ya da grupların araştırma sürecine katılmalarının daha kolay ya da ulaşılabilir olmaları durumları göz önünde bulundurulmuştur (Ekiz, 2009; Johnson \& Christensen 2004). Örneklemden elde edilen verilerin Türkiye'deki tüm kimya dersleriyle ilgili algısı olan öğrenci topluluğunu temsil ettiği 
iddia edilmemektedir. Ancak örneklem, açıklayıcı ve doğrulayıcı faktör analiziyle verilerin yap1 geçerliğinin incelenmesi için yeterince büyüktür (Büyüköztürk, 2002).

Veri Toplama Araçları

Çalışmada veri toplama araçları olarak "Kimya Algı Ölçeği-KAÖ”, “Íngilizce-Türkçe Uyumluluk Derecelendirme Formu” ve “Türkçe Anlaşılabilirlik Derecelendirme Formu” kullanılmıştır.

\section{Kimya Algl Ölçeği (KAÖ)}

Wells (2003) tarafından geliştirilen CPQ (Chemistry Perception Questionnaire)'un araştırmacının uzman görüşleri sonrasında orijinal ölçekte yer alan etnisite alt boyutunu ölçekten çıkartmasıyla yaptığı değişikliklerden sonra 6 alt boyuta ve 30 maddeye indirgenmiş olan İngilizce formu kullanılmıştır. Bu alt boyutlar; eğilim, tedirginlik, kimyanın kapsamı, cinsiyet, öğretim ve değer şeklindedir. 6 boyutlu kuramsal bir çerçevesi olan, çok boyutluluğu açımlayıcı faktör analizi ile saptanmış ve uygulanması uzun zaman almayan lise ve daha üst seviyelerde öğrenim gören öğrencilere yönelik bir algı ölçeğidir. Maddeler beşli likert tipinde oluşturulmuş ve kişilerin maddelere katılma dereceleri; Tamamen Katıliyorum (5), Katılıyorum (4), Kararsızım (3), Katılmıyorum (2) ve Tamamen Katılmıyorum (1) şeklinde sınıflandırılmıştır. Ölçekte yer alan maddelerden 10 tanesi olumlu ve 20 tanesi olumsuz olarak belirlenmiştir. Öğrencilerin vermiş olduğu cevapların puanlanmasında, olumlu maddeler 5, 4, 3, 2, 1 şeklinde, olumsuz maddeler ise 1, 2, 3, 4, 5 şeklinde bir puanlanmıştır. CPQ'dan alınabilecek toplam puanlar 30 ile 150 arasında değişmektedir. Amerika Birleşik Devletleri'nde (ABD) 282 öğrenci ile yapılan çalışmada yedi alt boyutta otuz beş maddeden oluşan ölçeğin güvenirliği test tekrar test yöntemiyle belirlenmiştir. Bir ay süreyle aynı öğrenci grubuna iki kez uygulanan ölçeğin alt boyutlarının Cronbach Alpha katsayılarının .725 ile .917 arasında değiştiği belirlenmiştir.

\section{İnilizce-Türkçe Uyumluluk Derecelendirme Formu}

Türkçe çevirinin orijinal maddeleri hangi oranda karşıladığını belirlemek için Baloğlu (2005) tarafından geliştirilen derecelendirme formu kullanılmıştır. $\mathrm{Bu}$ formun sol tarafına İngilizce orijinal maddeler, sağ tarafina ise Türkçe çeviriler yazılmıştır. Ortadaki alana ise “Tercüme Uygunluk Derecesi”ni belirten bir ölçek yerleştirilmiştir. Bu form yardımıyla İngilizce uzmanları, Eğer Türkçe çevirinin orijinal maddeyi hiç karşılamadığını düşünüyorlar ise sıfır (0); tamamen karşıladığını düşünüyorlar ise (10) sınırlarında; tercümenin uygunluğunu derecelendirmişlerdir. 


\section{Türkçe Anlaşılabilirlik Derecelendirme Formu}

Türkçe formdaki maddelerin, Türkçe dilbilgisine uygunluk ve anlaşılabilirlik düzeylerinin belirlenmesi amacıyla Baloğlu (2005) tarafından geliştirilen form kullanılmıştır. Türk dili uzmanları, formu kullanarak ölçek maddelerini Türkçe dili kuralları açısından derecelendirmişlerdir. Bu derecelendirmeyi, madde Türk dili kurallarına uymadığından hiç anlaşılmıyorsa sıfır (0), tamamen anlaşılıyorsa on (10) aralığında değerlendirerek yapmışlardır.

İşlem

Türkçe’ye uyarlanması çalışmasına başlanmadan önce, ölçeğin geliştiricisinden izin alınmıştır. Daha sonra, ölçek maddeleri araştırmacı tarafından Türkçe'ye tercüme edilmiştir. Türkçe'ye çevrilen ifadelerin İngilizce-Türkçe uyumluluğu ve Türkçe dilbilgisine uygunluğu ve anlaşılabilirliği İngilizce-Türkçe uyumluluk ve Türkçe anlaşılabilirlik derecelendirme formları kullanılarak belirlenmiştir. Formlar, uzmanlar tarafindan birbirinden bağımsız olarak doldurulmuştur. Uzman görüşleri doğrultusunda da araştırmacı tarafından Türkçe tercümede birtakım değişiklikler yapılmıştır.

Ölçeğin kavram ve dil eşitliğini sağlamak için, bir İngilizce dil uzmanı ölçeğin Türkçe maddelerinin İngilizceye geri çevirisini yapmıştır. Araştırmacı da, ölçeğin orijinal İngilizce maddeleri ve geri tercüme İngilizce maddeleri arasındaki benzerlikleri incelemiştir.

Tercüme ve Dil geçerliği sağlanan ölçeğin, önce İngilizce formu üç hafta sonrada Türkçe formu aynı öğrenci grubuna uygulanarak iki form arasındaki tutarlık derecesi incelenmiştir. Toplam 30 öğrencinin katıldığı bu aşamaya ait sonuçlara, Wilcoxon Eşleştirilmiş Çiftler Testi (Wilcoxon Signed Ranks Test) uygulanmıştır.

Ölçeğin çok boyutlu yapısı ise, geçerlik ve güvenirliği (psikometrik özellikleri) hakkında fikir elde etmek amacıyla 4 farklı üniversitedeki 435 öğrenciye uygulanmıştır. Güvenirlik analizi için Cronbach Alpha değerleri belirlenmiştir. Ölçeğin geçerliği için ise hem açımlayıcı (exploratory factor analysis) hem de doğrulayıcı faktör analizi (confirmatory factor analysis) uygulanmıştır.

\section{Verilerin Analizi}

Verilerin analizinde SPSS 15.0 ve LISREL 8.8 istatistik programları kullanılarak analizler yapılmıştır. 


\section{Bulgular}

Bu bölümde CPQ'un Türkçe'ye uyarlanması, güvenirlik ve geçerlik çalışmaları ele alınmıştır.

\section{Yapı, Kavram ve Dil Eşitliği}

KAÖ, alt1 alt boyut ve her birine ait beş olmak üzere toplam 30 maddeden oluşmaktadır (bakınız EK 1). Araştırmada ilk olarak İngiliz dil uzmanlarının her bir maddenin İngilizceTürkçe uyumunu derecelendirme düzeyleri belirlenmiştir (bakınız Tablo 1).

Tablo 1. Ölçek Maddeleri İngilizce-Türkçe Uyumu ve Türkçe Anlaşılabilirlik Dereceleri

\begin{tabular}{|c|c|c|c|c|}
\hline \multirow[b]{2}{*}{ Maddeler } & \multicolumn{2}{|c|}{ İngilizce-Türkçe Uyum } & \multicolumn{2}{|c|}{ Türkçe Anlaşılabilirlik } \\
\hline & $\overline{\mathrm{X}}$ & ss & $\overline{\mathrm{X}}$ & SS \\
\hline M1 & 8.87 & 2.10 & 9.50 & 1.22 \\
\hline M7 & 7.87 & 2.16 & 9.33 & 1.03 \\
\hline M13 & 9.62 & 1.06 & 9.66 & .81 \\
\hline M19 & 9.71 & .48 & 9.66 & .81 \\
\hline M25 & 9.42 & 1.51 & 9.60 & .89 \\
\hline M2 & 8.50 & 2.13 & 9.50 & 1.00 \\
\hline M8 & 9.75 & .70 & 9.80 & .44 \\
\hline M14 & 9.25 & 1.16 & 8.00 & 2.73 \\
\hline M20 & 9.50 & .75 & 9.60 & .89 \\
\hline M26 & 9.75 & .46 & 9.20 & 1.78 \\
\hline M3 & 8.50 & 2.32 & 9.20 & 1.09 \\
\hline M9 & 10.00 & .00 & 9.80 & .44 \\
\hline M15 & 9.62 & .51 & 8.75 & 2.50 \\
\hline M21 & 9.25 & 1.16 & 8.80 & 1.78 \\
\hline M27 & 9.00 & .75 & 8.60 & 2.60 \\
\hline M4 & 9.25 & 2.12 & 9.66 & .81 \\
\hline M10 & 9.87 & .35 & 9.40 & 1.34 \\
\hline M16 & 8.37 & 1.50 & 9.20 & 1.78 \\
\hline M22 & 10.00 & .00 & 9.50 & 1.22 \\
\hline M28 & 9.87 & .35 & 9.50 & 1.22 \\
\hline M5 & 9.87 & .35 & 9.75 & .50 \\
\hline M11 & 6.87 & 2.94 & 9.00 & 2.00 \\
\hline M17 & 9.75 & .46 & 9.16 & 2.04 \\
\hline M23 & 7.00 & 2.08 & 10.00 & .00 \\
\hline M29 & 8.37 & 2.26 & 9.60 & .89 \\
\hline M6 & 10.0 & .00 & 9.80 & .44 \\
\hline M12 & 9.37 & 1.06 & 9.66 & .81 \\
\hline M18 & 9.75 & .70 & 9.50 & 1.22 \\
\hline M24 & 9.00 & 2.07 & 9.50 & 1.22 \\
\hline M30 & 9.75 & .46 & 9.83 & .40 \\
\hline
\end{tabular}


Tablo 1 incelendiğinde ölçek maddelerinin tercümesinin İngilizce orjinali ile olan uyum düzeyleri 6.87 ile 10.00 arasında değiştiği belirlenmiştir $(\bar{X}=9.19 ; \quad$ ss=.57). Türk Dili ve Edebiyatı ve Türkçe alanı uzmanları ise her bir ifadenin Türkçe dil kurallarına uygunluğunu derecelendirmişlerdir. Tablo 1'den Türkçe anlaşılabilirliğin ise 8.00 ile 10.00 arasında değiştiği $(\overline{\mathrm{X}}=9.46 ; \mathrm{ss}=1.03)$ anlaşılmaktadır.

Daha sonra ölçeğin İngilizce ve Türkçe formuna ait sonuçların birbiriyle ne derecede örtüştüğünü tespit etmek amaciyla ölçeğin İngilizce form ile oluşturulan Türkçe form aynı öğrenci grubuna 3 haftalık ara ile uygulanmıştır. Toplam 30 öğrencinin katıldığı bu aşamaya ait Wilcoxon Eşleştirilmiş Çiftler Testi (Wilcoxon Signed Ranks Test) sonuçları Tablo 2'de sunulmuştur.

Tablo 2. Wilcoxon Eşleştirilmiş Çiftler Testi Sonuçları

\begin{tabular}{lccccc}
\hline Maddeler & $\mathrm{Z}$ & $\mathrm{p}<.05$ & Maddeler & $\mathrm{Z}$ & $\mathrm{p}<.05$ \\
\hline M1 & $-1.897^{\mathrm{a}}$ & .058 & M4 & $-.707^{\mathrm{a}}$ & .480 \\
M7 & $-.965^{\mathrm{b}}$ & .334 & M10 & $-1.386^{\mathrm{b}}$ & .166 \\
M13 & $-1.498^{\mathrm{a}}$ & .134 & $\mathrm{M} 16$ & $-1.166^{\mathrm{b}}$ & .244 \\
M19 & $-.257^{\mathrm{a}}$ & .797 & $\mathrm{M} 22$ & $-.905^{\mathrm{b}}$ & .366 \\
M25 & $-.504^{\mathrm{a}}$ & .614 & $\mathrm{M} 28$ & $-.277^{\mathrm{a}}$ & .782 \\
M2 & $-.504^{\mathrm{a}}$ & .614 & M5 & $-1.274^{\mathrm{a}}$ & .203 \\
M8 & $-.190^{\mathrm{b}}$ & .850 & $\mathrm{M} 11$ & $-1.809^{\mathrm{b}}$ & .070 \\
M14 & $-.914^{\mathrm{b}}$ & .361 & M17 & $-.855^{\mathrm{b}}$ & .392 \\
M20 & $-1.508^{\mathrm{a}}$ & .132 & M23 & $-1.653^{\mathrm{b}}$ & .098 \\
M26 & $-1.334^{\mathrm{a}}$ & .182 & M29 & $-.275^{\mathrm{b}}$ & .783 \\
M3 & $-1.428^{\mathrm{a}}$ & .153 & M6 & $-.406^{\mathrm{a}}$ & .684 \\
M9 & $-1.508^{\mathrm{b}}$ & .132 & M12 & $-.656^{\mathrm{a}}$ & .512 \\
M15 & $-1.294^{\mathrm{b}}$ & .196 & M18 & $-1.508^{\mathrm{b}}$ & .132 \\
M21 & $-1.364^{\mathrm{a}}$ & .172 & M24 & $-1.890^{\mathrm{b}}$ & .059 \\
M27 & $-.504^{\mathrm{a}}$ & .614 & M30 & $-.504^{\mathrm{b}}$ & .614 \\
\hline
\end{tabular}

${ }^{\mathrm{a}}$ Negatif siralar temelinde, ${ }^{\mathrm{b}}$ Pozitif siralar temelinde

Analiz sonuçları her iki forma ait sonuçların birbirleriyle yüksek oranlarda örtüştüğünü göstermiştir. Bu farkın istatistiksel olarak ( $p<.05)$ anlamlı olmadığı belirlenmiştir. $\mathrm{Bu}$ sonuç, ölçeğin İngilizce ve Türkçe formunun birbirleri ile tutarlı olduğunu yani öğrencilerin ölçeğin İngilizce ve Türkçe formundan aynı şeyleri anladıklarını ortaya koymuştur.

Ölçeğin Psikometrik Özellikleri (Yapı Geçerliği ve Güvenirlik)

\section{Madde Analizi}

Madde toplam korelasyonu, test maddelerinden alınan puanlar ile testin toplam puanı arasındaki ilişkiyi açıklamaktadır. Madde toplam korelasyonunun pozitif ve yüksek olmasının, maddelerin benzer davranışları örneklediğini ve testin iç tutarlılığının yükssek 
olduğunu göstermektedir (Büyüköztürk, 2012). Tablo 3'de anketin madde toplam korelasyonu verileri yer almaktadır.

Tablo 3. Anketteki Maddelere ait Madde Toplam Korelasyonları

\begin{tabular}{cccc}
\hline Madde No & $\begin{array}{c}\text { Madde-Toplam } \\
\text { Korelasyonlar1 (r) }\end{array}$ & Madde No & $\begin{array}{c}\text { Madde-Toplam } \\
\text { Korelasyonlar1 (r) }\end{array}$ \\
\hline M1 & $.276^{* *}$ & M16 & $.472^{* *}$ \\
M2 & $.308^{* *}$ & M17 & $.282^{* *}$ \\
M3 & $.240^{* *}$ & M18 & $.508^{* *}$ \\
M4 & $.373^{* *}$ & M19 & $.358^{* *}$ \\
M5 & $.420^{* *}$ & M20 & $.527^{* *}$ \\
M6 & $.433^{* *}$ & M21 & $.342^{* *}$ \\
M7 & $.399^{* *}$ & M22 & $.450^{* *}$ \\
M8 & $.612^{* *}$ & M23 & $.550^{* *}$ \\
M9 & $.480^{* *}$ & M24 & $.447 * *$ \\
M10 & $.421^{* *}$ & M25 & $.454^{* *}$ \\
M11 & $.292^{* *}$ & M26 & $.476^{* *}$ \\
M12 & $.297^{* *}$ & M27 & .043 \\
M13 & $.409^{* *}$ & M28 & $.500^{* *}$ \\
M14 & $.309^{* *}$ & M29 & $.276^{* *}$ \\
M15 & $.206^{* *}$ & M30 & $.451^{* *}$ \\
\hline
\end{tabular}

**Korelasyon 0.01 düzeyde anlamlı farklıdır.

Tablo 3 incelendiğinde, 27. madde dışındaki diğer tüm maddelerin puanları anket puanı ile yüksek derecede korelasyon gösterdiği ve $\mathrm{p}<.01$ düzeyinde anlamlı olduğu görülmektedir. Madde analizi sonucuna göre 27. madde ölçekten çıkarılmıştır.

Yapı geçerliği

CPQ'un yapı geçerliğini belirlemek için Açımlayıı Faktör Analizi (AFA) ve Doğrulayıcı Faktör Analizi (DFA) yapılmıştır. AFA birbirleri ile ilişkili çok sayıda değişkenden, bu değişkenlerin birlikte açıklayabildikleri az sayıda ve anlamlı faktöre ulaşmayı hedefler (Çokluk, Şekercioğlu \& Büyüköztürk, 2012). DFA ise değişkenlerden oluşturulan faktörlerin gerçek değerlere uygunluğunu incelemek için kullanılır. Bu çalışmada AFA, CPQ’un Türk öğrenciler üzerindeki yapısını açığa çıkarmak için, DFA ise formun faktör yapısının Türk öğrenciler üzerinde doğrulanıp doğrulanmadığını incelemek için kullanılmıştır (Çokluk, Şekercioğlu \& Büyüköztürk, 2012).

Açımlayıcı Faktör Analizi

CPQ'un yapı geçerliğini belirlemek için açımlayıcı faktör analizi yapılarak bütün maddeler arasında korelasyon matrisi incelenmiştir. Verilerin faktör analizine uygunluğunu 
belirlemek için "KMO" (Kaiser-Meyer-Olkin) katsayısı ve "Bartlett Küresellik" testleri yapılmıştır. Verilerin faktör analizine uygun olması için KMO’nun .50'den yüksek olması ve Bartlett Küresellik testinin de anlamlı çıkması gerekmektedir (Çokluk, Şekercioğlu \& Büyüköztürk, 2012; Kalaycı, 2009). Bu çalışmada KMO .833, Bartlett Küresellik testi $\chi^{2}$ değeri ise $3381.364(\mathrm{p}<.001)$ bulunmuştur.

AFA'da varimax dik döndürmesi kullanılmıştır. Bu işlem sonucunda, ölçekte bulunan maddeler 5 faktör altında toplanmıştır. Binişik olduğu tespit edilen 5, 7, 8, 11, 17, 20, 23, 25. ve 29. maddeler ölçekten çıkarılarak yeniden faktör analizi yapılmıştır. Analizin sonucunda KMO değeri .796 ve Bartlett Küresellik testi $\chi^{2}$ değeri ise $2029.238(\mathrm{p}<.001)$ olarak elde edilmiştir. 20 madde ve 5 faktörden oluşan ölçme aracının toplam varyansın \%54.743'ünü açıkladığı ve alt faktörlerde yer alan maddelerin orijinal formdaki maddelerle örtüştüğü görülmüştür. Ölçeğin faktör yükleri ve açıkladıkları varyans oranlarına ilişkin bilgiler Tablo 4'de sunulmuştur.

Tablo 4. CPQ'daki Faktör Yükleri

\begin{tabular}{|c|c|c|c|c|c|}
\hline Madde & Cinsiyet & Değer & Tedirginlik & $\begin{array}{c}\text { Kimyanın } \\
\text { kapsamı }\end{array}$ & Eğilim \\
\hline 22 & .832 & & & & \\
\hline 10 & .822 & & & & \\
\hline 16 & .816 & & & & \\
\hline 28 & .798 & & & & \\
\hline 4 & .732 & & & & \\
\hline 30 & & .762 & & & \\
\hline 6 & & .686 & & & \\
\hline 24 & & .639 & & & \\
\hline 18 & & .596 & & & \\
\hline 12 & & .546 & & & \\
\hline 14 & & & .817 & & \\
\hline 2 & & & .777 & & \\
\hline 26 & & & .723 & & \\
\hline 15 & & & & .709 & \\
\hline 3 & & & & .651 & \\
\hline 9 & & & & .610 & \\
\hline 21 & & & & .442 & \\
\hline 1 & & & & & .669 \\
\hline 13 & & & & & .629 \\
\hline 19 & & & & & .617 \\
\hline$\% 54.743$ & $\% 16.613$ & $\% 12.115$ & $\% 10.339$ & $\% 8.348$ & $\% 7.328$ \\
\hline
\end{tabular}

AFA ile elde edilen alt boyutlardan ilki cinsiyettir. $\mathrm{Bu}$ alt boyut 5 maddeden oluşmaktadır ve toplam varyansın \%16.613'ünü açıklamaktadır. Cinsiyet alt boyutunun faktör yükleri .832 ile .732 arasında değişmektedir. Değer adlı ikinci alt boyut 5 maddeden 
oluşmaktadır. Bu alt boyut ise toplam varyansın \%12.115'ini açıklamaktadır. Faktör yükleri ise .762 ile .546 arasında değişmektedir. Üçüncü alt boyut olan tedirginlik alt boyutu 3 maddeden oluşmaktadır. Bu boyut toplam varyansın \%10.339'unu açıklamakta ve faktör yükleri .817 ile .723 arasında değişmektedir. Dördüncü alt boyut ise kimyanın kapsamıdır. $\mathrm{Bu}$ alt boyut ise 4 maddeden oluşmakta olup, varyansın \%8.348'ini açıklamakta ve faktör yükleri .709 ile 442 arasında değişmektedir. Eğilim adlı beşinci alt boyut 3 maddeden oluşmakta olup, varyansın \%7.328'ini açıklamakta ve faktör yükleri 669 ile .617 arasında değişmektedir.

\section{Doğrulayıcı Faktör Analizi}

Son yıllarda sosyal bilimler ve davranış bilimlerindeki yapısal eşitlik modellemesinin (structural equation modeling) önemi ve kullanma sıklığı gittikçe artmaktadır (Şimşek, 2007). Yapısal eşitlik modellemesi tek bir istatistiksel teknik değil, faktör analizi, yol analizi, çoklu grup uygulamaları gibi istatistik teknikleri içeren bir tekniktir. (Çokluk, Şekercioğlu \& Büyüköztürk, 2012). Amos, EQs ve LISREL, gibi daha pek çok istatistik paket programı yardımıyla doğrulayıcı faktör analizi yapılabilmektedir. Uyarlanma çalışması yapılan ölçeğin Türkçe formuna orijinal ölçekte yapılmamasına rağmen LISREL 8.8 istatistik programı ile doğrulayıcı faktör analizi yapılmış ve açımlayıcı faktör analizi çalışmasıyla belirlemiş olduğumuz faktör yapılarının doğrulanıp doğrulanmadığı test edilmiştir (bakınız Şekil 1).

Yapısal eşitlik modellemesinde analizler için çok sayıda uyum istatistiği bulunmaktadır. $\mathrm{Bu}$ çalışmada en sık kullanılan uyum istatistiği indeksleri bildirilmiştir. Beklenen kovaryans matrisi ile gözlenen kovaryans matrisi arasındaki farkın ( $\chi^{2}$ değerinin) manidarlı̆̆ hakkında bilgi edinmek için p değeri incelenmiştir. p değerinin anlamlı olmaması arzu edilmesine rağmen örneklem büyüklüğünün büyük olduğu çalışmalarda olduğu gibi bu çalışmada da p değerin manidar olması tolere edilmektedir (Çokluk, Şekercioğlu \& Büyüköztürk, 2012).

$\chi^{2}$ değerinin kendi serbestlik derecesine oranı önemli bir istatistiktir. Bu oranın 3 veya 3'ün altında olması uyumun çok iyi olduğunu göstermektedir. Bu çalışmada $\chi^{2} / \mathrm{sd}$ oranı $2.88^{\prime}$ dir. $\mathrm{Bu}$ durumda ankete ait $\chi^{2} /$ sd oranı mükemmel uyum göstermektedir. GFI, AGFI, CFI ve NNFI değerlerinin .90'un üzerinde olması uyumun iyi olarak kabul edilmesi için yeterlidir. Ölçeğe ait değerler incelendiğinde GFI değerinin .90, AGFI değerinin .87, NNFI değerinin .90 ve CFI değerinin ise .92 olması bu değerlerin iyi uyum gösterdiğini göstermektedir. 


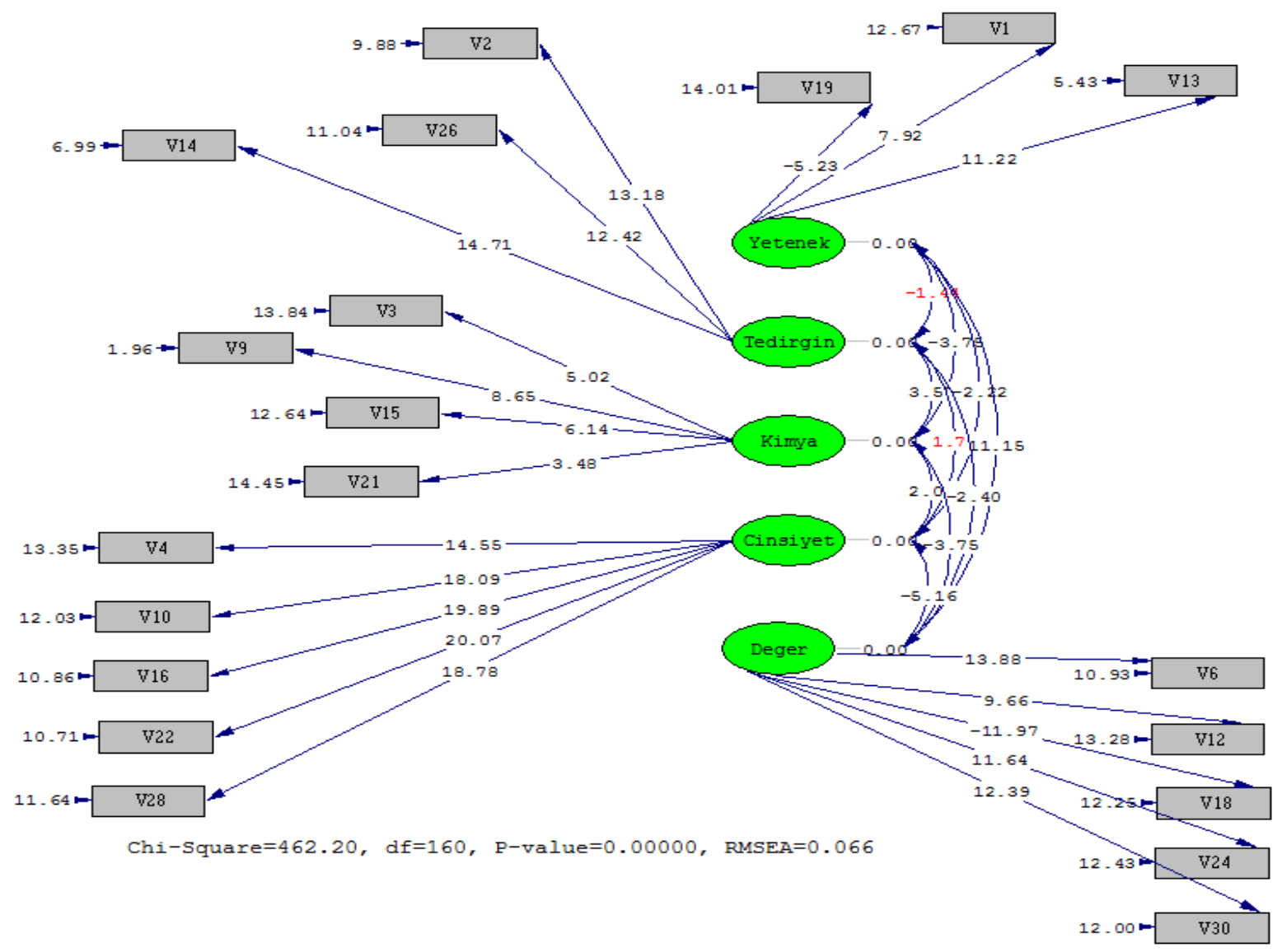

Şekil 1. Doğrulayıcı Faktör Analizi Sonucunda Ölçeğe ait Yol Analizi ve Faktör Yük Değerleri

Teste ait RMSEA değerinin .066 olduğu görülmektedir. RMSEA değerinin .05 'den küçük olması mükemmel ve .08'den küçük olması iyi uyuma işaret etmektedir. Bu durumda ölçeğimize ait RMSEA değeri de iyi uyum göstermektedir. RMR ve standardize edilmiş RMR değerlerinin .05'in altında olması mükemmel uyuma, .08'in altında olması iyi uyuma karşılık gelmektedir. Ölçeğe ait RMR (.072) ve standardize edilmiş RMR (.069) değerleri incelendiğinde, RMR ve standardize edilmiş RMR değerlerinin iyi uyum gösterdiği söylenebilir.

Uyum istatistikleri incelendiğinde Türkçe'ye çevrilerek uyarlaması yapılan bu ölçeğin, bütün uyum istatistikleriyle iyi bir model oluşturduğu ve faktör yapılarıyla geçerli bir ölçek olduğu yorumu yapılabilmektedir.

\section{Güvenirlik}

Kimya Alg1 Ölçeği'nden 10 madde çıkarılarak oluşturulan 20 maddelik ölçeğin tamamı için Cronbach Alpha güvenirlik katsayısı 745 bulunmuştur. Beş boyutuna ait değerler ise .445 ile .864 arasında değişmiştir (bakınız tablo 5). 
Tablo 5. Orijinal ve Türkçe Kimya Algı Ölçeği’nin ve Alt boyutlarının Cronbach Alpha Güvenirlik Katsayıları

\begin{tabular}{lll}
\hline & Orjinal & Türkçe \\
\hline Cinsiyet & .917 & .864 \\
Değer & .776 & .698 \\
Tedirginlik & .847 & .735 \\
Kimyanın Kapsamı & .857 & .495 \\
Eğilim & .878 & .445 \\
Etnisite & .914 & \\
Öğretim & .725 & \\
\hline Toplam & .949 & .745 \\
\hline
\end{tabular}

Tablo 5 incelendiğinde Türkçe KAÖ’nin genel Cronbach Alpha güvenirlik katsayısı .745 olarak bulunması ölçeğin yüksek derecede güvenilir olduğunu göstermektedir. Ayrıca ölçeğin beş alt boyutuna ait Cronbach Alpha değerlerine bakıldığında da alt boyutların ortayüksek düzeyde güvenilir olduğu sonucuna ulaşılmaktadır.

\section{Tartışma}

$\mathrm{Bu}$ araştırmada, Wells (2003) tarafından geliştirilen "Chemistry Perception Questionnaire” (Kimya Algı Ölçeği) isimli ölçeğin Türkçe’ye uyarlanması çalışması yapılmıştır. Ölçeğin, beş boyutlu kuramsal bir çerçeveye sahip olduğu belirlenmiştir. Ölçeğin diğer önemli özelliği ise, ölçek verilerinin çok boyutluluğunun hem açımlayıcı hem de doğrulayıcı faktör analizi ile başarılı bir şekilde saptanmış olmasıdır. Bu boyutlar okuldaki kimya derslerine yönelik çok boyutlu bir ölçüm yapma olanağı vermektedir. Ölçeğin dilsel eşdeğerlik çalışmasından elde edilen bulgular Türkçe ve orijinal formda bulunan maddelerin arasındaki korelasyonun oldukça yüksek olduğunu göstermiştir.

KAÖ’nin yapı geçerliği için açımlayıcı ve doğrulayıcı faktör analizleri uygulanmıştır. 1 maddenin (27. madde) puanları anket puanı ile yüksek derecede korelasyon göstermediğinden ve $\mathrm{p}<.01$ düzeyinde anlamlı sonuç vermediğinden ölçekten çıkartılmıştır. Ayrıca, binişik olduğu tespit edilen 9 madde de ölçekten çıkartılmıştır. Toplam on maddenin ölçekten çıkartılmasıyla geriye kalan maddeler için yapılan açımlayıcı faktör analizi sonuçları ölçeğin cinsiyet, değer, tedirginlik, kimyanın kapsamı ve eğilim olmak üzere beş alt boyuttan oluştuğunu göstermiştir. Bu beş alt boyut toplam varyansın \%54.743'ünü açıklamıştır. Ölçek geliştirme ve uyarlama çalışmalarında açıklanan varyans oranı için $\% 30$ ve üzerinde olması ölçüt olarak kabul edildiğinden ölçeğin yapı geçerliğinin sağlandığı söylenebilir (Ural \& Kılıç, 2006). Diğer bir faktör analizi olan DFA için uyum indeksi sınırları göz önüne 
alındığında, modelin iyi düzeyde uyum verdiği söylenebilir. Ölçeğin güvenirliğine ait veriler ise, ölçeğin tamamına ait Cronbach Alpha değerinin .745, beş boyuta ait değerlerin ise .445 ile .864 arasında değiştiğini göstermiştir.

\section{Sonuç ve Öneriler}

Elde edilen tüm bulgular, ölçeğinin tercüme ve dil geçerliği, yapı geçerliği (beş boyutlu yapıya) ve de güvenirliğine destek vermektedir. Böylece, ölçek üniversite öğrencilerinin kimya derslerine karşı algılarını ölçme imkânı sağlamaktadır. Öğretmenler tarafından öğrencilerin kimya derslerine karşı alg1 düzeyleri belirlenerek, uygun farklı iş olanakları/öğretim teknikleri tavsiye edilebilir. Ayrıca öğrencilerde var olan pozitif alg1 güçlendirilebilir. Negatif algılar ise düzeltilerek öğretmenlere, öğrencilerin daha başarılı olmaları için gerekli önlemleri alma imkânı sağlanabilir. Farklı örneklem grupları ile yürütülecek araştırmalarla "Kimya Dersi Algı Ölçeği’nin” Türkçe formun geçerlik ve güvenirliğine ilişkin yeni kanıtlar sağlanabilir.

\section{Kaynakça}

Baloğlu, M. (2005). Matematik kaygısı derecelendirme ölçeği’nin Türkçe'ye uyarlanması, dil geçerliği ve ön psikometrik incelemesi. Kuram ve Uygulamada Ĕgitim Bilimleri Dergisi, 5 (1), 7-30.

Barman, C. R. (1997). Students' views of scientists and science: Results from national study. Science and Children, 35 (1),18-23.

Bowen, C. W. (1999). Development and score validation of a chemistry laboratory anxiety instrument (CLAI) for college chemistry students. Educational and Psychological Measurement, 59 (1), 171-185.

Burkam, D. T., Lee, V. E., \& Smerdon, B. A. (1997). Gender and science learning early in high school: Subject matter and laboratory experiences. American Educational Research Journal, 34 (2). 297-331.

Büyüköztürk, Ş. (2002). Faktör analizi: temel kavramlar ve ölçek geliştirmede kullanımı. Kuram ve Uygulamada Ĕ̈itim Yönetimi, 32, 470-483.

Büyüköztürk, Ş., Kılıç-Çakmak, E., Akgün, Ö. E., Karadeniz, Ş. \& Demirel, F. (2010). Bilimsel araştırma yöntemleri (6. Baskl). Ankara: Pegem A Akademi.

Büyüköztürk, Ş. (2012). Sosyal bilimler için veri analizi el kitabı (16. Baskl). Ankara: Pegem A Yayıncilik. 
Cost. M.G. (2000). College student perceptions of science teachers and the effect on science teaching as a career path. Unpublished doctoral dissertation, Syracuse University.

Çokluk, Ö., Şekercioğlu, G. \& Büyüköztürk, Ş. (2012). Sosyal bilimler için çok değişkenli istatistik: SPSS ve LISREL uygulamaları (2. Baskl). Ankara: Pegem Akademi.

Deboer, G.E. (1987). Predicting continued participation in college chemistry for men and women. Journal of Research in Science Teaching, 24 (6), 527-538.

Eddy, R. M. (1996). Chemophobia in the college classroom: Extent, sources, and student characteristics. Unpublished doctoral dissertation. University of Pittsburgh.

Ekiz, D. (2009). Bilimsel araştırma yöntemleri: yaklaşım, yöntem ve teknikler. Geliştirilmiş 2. Baskı, Anı Yayınc1lık, 226 s, Ankara.

Greenfield, T. A. (1997). Gender-and grade-level differences in science interest and participation. Science Education, 81, 259-276.

Johnson, B. \& Christensen, L. (2004). Educational research: Quantitative, qualitative and mixed approaches. Pearson Education, Inc., Second Edition, 562 p, Boston.

Kalaycı, Ş. (2009). SPSS Uygulamalı çok değişkenli istatistik teknikleri (4. Baskı). Ankara: Asil Yayınları.

Karasar, N. (2005). Bilimsel araştırma yöntemi (15. Baskı). Ankara: Nobel Yayın Dağıtım.

Koballa, T.R.Jr. (1988). Attitude and related concepts in science education. Science Education, 72 (2), 115-126.

Lawrenz, F. (1976). Student perception of the classroom learning environment in biology, chemistry, and physics courses. Journal of Research in Science Teaching, 13 (4), 315323.

MEB, Talim Terbiye Kurulu Başkanlığı (2011). Ortaöğretim 9.10.11. ve 12. sinıf kimya dersi ögretim programı. http://ttkb.meb.gov.tr/program2.aspx (21 Ekim 2012).

McMillan, J.H. \& Schumacher, S. (2006). Research in education: evidence-based inquiry (6th Edition). Boston: Pearson.

Ost, D.H. \& White, R.S. (1979). Attitudes about scientist: An inventory for use in teaching or research, School Science and Mathematics, 79 (2), 133-139.

Peterson, K.D. \& Yaakobi, D. (1979). Self-concept and perceptions of role behavior of high school science students and teachers: New assessment instruments. Journal of Research in Science Teaching, 16 (5), 433-438. 
Rennie, L. J., \& Dunne, M. (1994). Gender, ethnicity, and students' perceptions about science and science-related careers in Fiji. Science Education, 78 (3), 285-300.

Şencan, H. (2005). Sosyal ve davranışsal ölçümlerde güvenilirlik ve geçerlilik. Ankara: Seçkin Yayıncılık.

Şimşek, Ö.F. (2007). Yapısal eşitlik modellemesine giriş (temel ilkeler ve LISREL uygulamalarl). Ankara: Ekinoks Yayınları.

Ural, A. \& Kılıç, İ. (2006). Bilimsel araştırma süreci ve SPSS ile veri analizi (Genişletilmiş 2. Baskl). Ankara: Detay Yayıncılık.

Yager, R.E. \& Bonnstetter, R.J. (1984). Student perceptions of science teachers, classes and course content. School Science and Mathematics, 84 (5), 406-414.

Wells, R.R. (2003). The development of an instrument to assess chemistry perceptions. Doctoral Dissertation. Texas Tech University. 


\section{Ek-1: Kimya Algı Ölçeği}

\begin{tabular}{|c|c|c|c|c|c|c|}
\hline No & Kimya Alg1 Ölçeği & 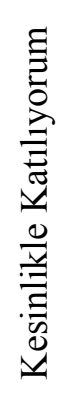 & 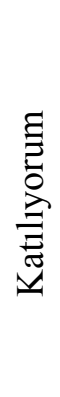 & 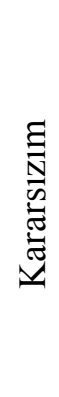 & 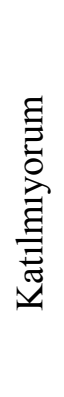 & 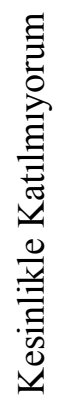 \\
\hline 1 & Kimya dersini ilginç buluyorum. & & & & & \\
\hline 2 & $\begin{array}{l}\text { Kimya laboratuvarlarında araştırma yaparken yaralanmaktan } \\
\text { korkuyorum. }\end{array}$ & & & & & \\
\hline 3 & Kimya bilimi, çok fazla matematik içermektedir. & & & & & \\
\hline 4 & Kimya alanında erkekler, bayanlara göre daha iyidir. & & & & & \\
\hline 5 & Kimya dersine çalışmak çok fazla zaman almaktadır. & & & & & \\
\hline 6 & Kimya, toplumu olumlu yönde etkilemektedir. & & & & & \\
\hline 7 & $\begin{array}{l}\text { Kimyada başarılı olmak için yeterli fen altyapısına sahip } \\
\text { değilim. }\end{array}$ & & & & & \\
\hline 8 & Kimya dersinin adını duymak bile beni korkutuyor. & & & & & \\
\hline 9 & Kimya bilimi çok zordur. & & & & & \\
\hline 10 & Bayanların kimyada başarılı olması beklenmez. & & & & & \\
\hline 11 & $\begin{array}{l}\text { Kimya dersleri, bilime ilgisi olmayanları elemek üzere } \\
\text { tasarlanmaktadır. }\end{array}$ & & & & & \\
\hline 12 & Herkes, biraz kimya bilmelidir. & & & & & \\
\hline 13 & İyi bir kimyacı olabilirim. & & & & & \\
\hline 14 & $\begin{array}{l}\text { Kimya dersi işlenirken tehlikeli kimyasallara maruz kalabilirim } \\
\text { diye korkuyorum. }\end{array}$ & & & & & \\
\hline 15 & Kimya biliminde çok fazla konu ve kavram vardır. & & & & & \\
\hline 16 & Kimya, erkeklere özgü bir bilim dalıdır. & & & & & \\
\hline 17 & Kimya eğitmenleri, iyi öğretmenlerdir. & & & & & \\
\hline 18 & Kimya, yarardan çok zarar verir. & & & & & \\
\hline 19 & $\begin{array}{l}\text { Kimyada başarılı olabilmek için yeterli matematik ön bilgisine } \\
\text { sahip değilim. }\end{array}$ & & & & & \\
\hline 20 & Kimya, beni tedirgin ediyor. & & & & & \\
\hline 21 & Kimya bilimi, ilişkisiz birçok olguyu öğrenmeyi gerektirir. & & & & & \\
\hline 22 & Kimya, erkekler için daha kolaydır. & & & & & \\
\hline 23 & $\begin{array}{l}\text { Bugüne kadar aldığım diğer fen dersleri, beni kimyaya karşı } \\
\text { soğuttu. }\end{array}$ & & & & & \\
\hline 24 & Kimya, yaşamımı iyileştirdi. & & & & & \\
\hline 25 & Kimya bilimini daha çok bilmek isterim. & & & & & \\
\hline 26 & Kimya laboratuvarında çalışmak beni tedirgin ediyor. & & & & & \\
\hline 27 & $\begin{array}{l}\text { Kimyada başarılı olabilmek için bilimsel bir zihin yapısına } \\
\text { sahip olmak zorundayız. }\end{array}$ & & & & & \\
\hline 28 & Kimya, bayanlar için daha zordur. & & & & & \\
\hline 29 & Kimya dersleri çok çabuk bitiyor. & & & & & \\
\hline 30 & Kimya, günlük yaşam problemlerini çözmek için yararlıdır. & & & & & \\
\hline
\end{tabular}




\section{Ek-2: Kimya Algı Ölçeği}

(Ölçeğin Faktör Analizi Yapıldıktan Sonra 20 Maddelik Hali)

Kimya Alg1 Ölçeği

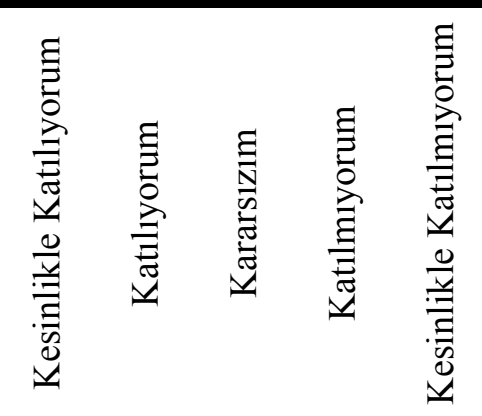

\begin{tabular}{|c|c|c|c|c|c|}
\hline \multicolumn{6}{|l|}{ Cinsiyet } \\
\hline Kimya alanında erkekler, bayanlara göre daha iyidir. & 5 & 4 & 3 & 2 & 1 \\
\hline Bayanların kimyada başarılı olması beklenmez. & 5 & 4 & 3 & 2 & 1 \\
\hline Kimya, erkeklere özgü bir bilim dalıdır. & 5 & 4 & 3 & 2 & 1 \\
\hline Kimya, erkekler için daha kolaydır. & 5 & 4 & 3 & 2 & 1 \\
\hline Kimya, bayanlar için daha zordur. & 5 & 4 & 3 & 2 & 1 \\
\hline \multicolumn{6}{|l|}{ Değer } \\
\hline Kimya, toplumu olumlu yönde etkilemektedir. & 5 & 4 & 3 & 2 & 1 \\
\hline Herkes, biraz kimya bilmelidir. & 5 & 4 & 3 & 2 & 1 \\
\hline Kimya, yarardan çok zarar verir. & 5 & 4 & 3 & 2 & 1 \\
\hline Kimya, yaşamımı iyileştirdi. & 5 & 4 & 3 & 2 & 1 \\
\hline Kimya, günlük yaşam problemlerini çözmek için yararlıdır. & 5 & 4 & 3 & 2 & 1 \\
\hline \multicolumn{6}{|l|}{ Tedirginlik } \\
\hline $\begin{array}{l}\text { Kimya laboratuvarlarında araştırma yaparken yaralanmaktan } \\
\text { korkuyorum. }\end{array}$ & 5 & 4 & 3 & 2 & 1 \\
\hline $\begin{array}{l}\text { Kimya dersi işlenirken tehlikeli kimyasallara maruz kalabilirim diye } \\
\text { korkuyorum. }\end{array}$ & 5 & 4 & 3 & 2 & 1 \\
\hline Kimya laboratuvarında çalışmak beni tedirgin ediyor. & 5 & 4 & 3 & 2 & 1 \\
\hline \multicolumn{6}{|l|}{ Kimyanın Kapsamı } \\
\hline Kimya bilimi, çok fazla matematik içermektedir. & 5 & 4 & 3 & 2 & 1 \\
\hline Kimya bilimi çok zordur. & 5 & 4 & 3 & 2 & 1 \\
\hline Kimya biliminde çok fazla konu ve kavram vardır. & 5 & 4 & 3 & 2 & 1 \\
\hline Kimya bilimi, ilişkisiz birçok olguyu öğrenmeyi gerektirir. & 5 & 4 & 3 & 2 & 1 \\
\hline \multicolumn{6}{|l|}{ Ĕgilim } \\
\hline Kimya dersini ilginç buluyorum. & 5 & 4 & 3 & 2 & 1 \\
\hline İyi bir kimyacı olabilirim. & 5 & 4 & 3 & 2 & 1 \\
\hline $\begin{array}{l}\text { Kimyada başarılı olabilmek için yeterli matematik ön bilgisine sahip } \\
\text { değilim. }\end{array}$ & 5 & 4 & 3 & 2 & 1 \\
\hline
\end{tabular}

